\title{
Calculating Calf Performance in Beef Operations: The University of Florida Beef Herds in the 2019-2020 Calving Season ${ }^{1}$
}

\author{
Mario Binelli, Angela M. Gonella-Diaza, Thiago Martins, Cecilia C. Rocha, Felipe A. C. C. \\ Silva, Federico Tarnonsky, Sergio Roskopf, Owen Rae, Danny Driver, Nicolas DiLorenzo, Jose \\ Dubeux, and David Thomas ${ }^{2}$
}

\section{Introduction}

For the many cow-calf operations in Florida, a major portion of the bottom line for the producer comes from the sale of weaned calves. Efficiency of a production system can be calculated as:

\section{Pounds of calves weaned / Number of females that started the breeding season.}

The two main components of this equation are reproductive performance (i.e., the calving rate) and the calf performance. This article aims to report the calf performance of two beef herds of the University of Florida, located in north (UF/IFAS NFREC, Marianna) and central Florida (Beef Units, Gainesville). This report will be updated annually to provide a moving benchmarking target for the beef industry in Florida. A companion Ask IFAS publication addresses the other component affecting producers' bottom line, which is reproductive performance (Calculating
Reproductive Performance in Beef Operations: The University of Florida Beef Herds 2019 Breeding Season). This report is designed for county faculty educating producers on the subject of calf performance and producers who may need a reference point to benchmark the performance on the operation.

The ultimate measure of calf performance is weaning weight, which will translate into remuneration to the producer. Weaning weight is the final compounded result of birth weight, weight gained from birth to weaning, and age at weaning. These variables are influenced by aspects such as the dam's milk production, herd health, forage and nutritional program, the calf's genetic potential, and environmental factors (e.g., rain and temperature). Some of these factors can be better controlled than others. The use of an estrus synchronization protocol at the beginning of the breeding season will stimulate cyclicity both in prepubertal heifers and in postpartum cows. This is expected to result in early breeding and early calving, a longer interval

1. This document is AN384, one of a series of the Department of Animal Sciences, UF/IFAS Extension. Original publication date February 2022. Visit the EDIS website at https://edis.ifas.ufl.edu for the currently supported version of this publication.

2. Mario Binelli, PhD, assistant professor, Department of Animal Sciences; Angela M. Gonella-Diaza, DVM, PhD, assistant professor, UF/IFAS North Florida Research and Education Center, Marianna, FL; Thiago Martins, DVM, PhD, postdoctoral fellow, Department of Animal Sciences; Cecilia C. Rocha, DVM, Department of Animal Sciences; Felipe A. C. C. Silva, DVM, Department of Animal Sciences; Federico Tarnonsky, DVM, UF/IFAS North Florida Research and Education Center, Marianna, FL; Sergio Roskopf, DVM, UF/IFAS North Florida Research and Education Center, Marianna, FL; Owen Rae, DVM, professor, Department of Large Animal Clinical Sciences, UF College of Veterinary Medicine; Danny Driver, MSc, general manager, Department of Animal Sciences; Nicolas DiLorenzo, PhD, professor, UF/IFAS North Florida Research and Education Center, Marianna, FL; Jose Dubeux, PhD, professor, UF/IFAS North Florida Research and Education Center, Marianna, FL; and David Thomas, general manager, UF/IFAS North Florida Research and Education Center, Marianna, FL; UF/IFAS Extension, Gainesville, FL 32611.

The Institute of Food and Agricultural Sciences (IFAS) is an Equal Opportunity Institution authorized to provide research, educational information and other services

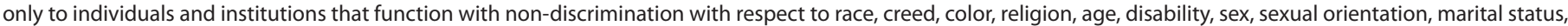

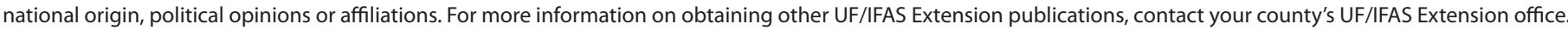
U.S. Department of Agriculture, UF/IFAS Extension Service, University of Florida, IFAS, Florida A \& M University Cooperative Extension Program, and Boards of County Commissioners Cooperating. Andra Johnson, dean for UF/IFAS Extension. 
for calf growth between calving and weaning and, consequently, heavier weaning weights. If the estrus synchronization protocol is combined with artificial insemination, then the genetics of the calf may be influenced to favor lower birth weights (which is desirable for calving ease and calf survival) and greater weight gains that will generate an even more favorable product for marketing. Consider the following rough calculations:

- An operation weans 100 calves at an average age of 240 days.

- Consider a $70 \mathrm{lb}$ average birth weight.

- Consider a $550 \mathrm{lb}$ average weaning weight.

- The average weight gain is: $550-70=480 \mathrm{lb}$.

- The average weight gain for the calf crop is: $480 \times 100=$ $48,000 \mathrm{lb}$.

- The average daily weight gain for the calf crop is: 48,000 $\mathrm{lb} / 240$ days $=200 \mathrm{lb} /$ day .

- A mere 10 days' decrease on average age at weaning results in 2,000 lb less on total calf weight for sale.

- Considering calf prices at $\$ 1.50 / \mathrm{lb}$ (i.e., $\$ 150 / \mathrm{cwt}$ ), this corresponds to $\$ 3,000$ less in the producer's bottom line.

Thus, once a weaning date is established, management efforts directed to increase the age at weaning, such as early breeding and consequently early calving, will increase pounds of calf for marketing and revenue to the producer.

\section{Calf Performance of UF Beef Herds}

There are many particularities in cow-calf operations across Florida, but producers may find it useful to utilize the numbers on this report as a reference point to gauge the reproductive performance of calves in their operations. Here, we present a yearly report of the calf performance of the University of Florida beef herds. Each University herd operates according to the respective regional characteristics and specific management (Table 1 and Figure 1). Birth weight and weaning weight data for both the Gainesville (Beef Unit) and the Marianna (UF/IFAS North Florida Research and Education Center) herds for the 2019-2020 calving season are presented in Figures 2 and 3.

This report indicates that birth weights were slightly less for females than males and similar across female categories, except for yearling heifers in the Marianna herd, which were inseminated with calving-ease bulls. Additionally, AI calves weaned at heavier body weights. In Marianna, AI male and female calves were $31 \mathrm{lb}$ and $50 \mathrm{lb}$ heavier than calves from natural service, respectively. In Gainesville, AI male and female calves were $56 \mathrm{lb}$ and $78 \mathrm{lb}$ heavier than calves from natural service, respectively. Such differences confirm the advantage of breeding early, and, consequently, calving earlier in the season. If the results in your operation vary too widely, contact your county livestock Extension agent or your state specialists for guidance.

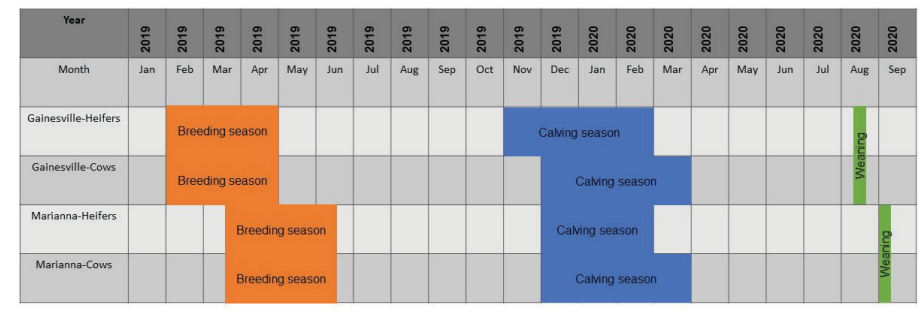

Figure 1. Calendar distribution of the 90-day breeding season (orange), calving season (blue), and weaning (green) of the UF beef herds. In both herds, the breeding season started when females were artificially inseminated, following a synchronization protocol. Cleanup bulls were introduced a few days after $\mathrm{Al}$ and removed at the end of the breeding season. The calving season is consistent with the breeding season (for an average 285-day gestation): Al calves were born first and calves from natural service followed. Weaning date was predetermined by the ranch management.

Credits: UF/IFAS
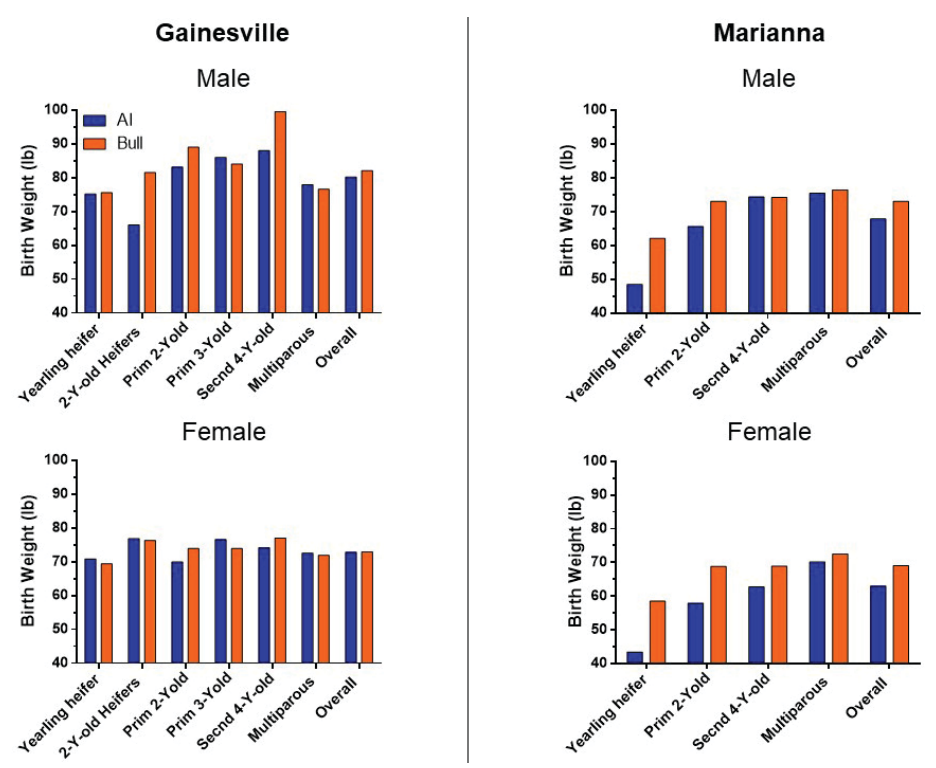

Figure 2. Birth weights for male and female calves from both the Gainesville (left panels) and the Marianna (right panels) herds, for each female category. Blue bars correspond to calves born from Al and orange bars correspond to calves sired by natural service. Credits: UF/IFAS

\section{Acknowledgments}

We thank the Gainesville and the Marianna Beef Units' staff and students who collaborated with data collection and compilation. We are grateful to Zoetis for the donation of synchronization drugs (Gainesville and Marianna) and Select Sires for the donation of semen (Marianna). 

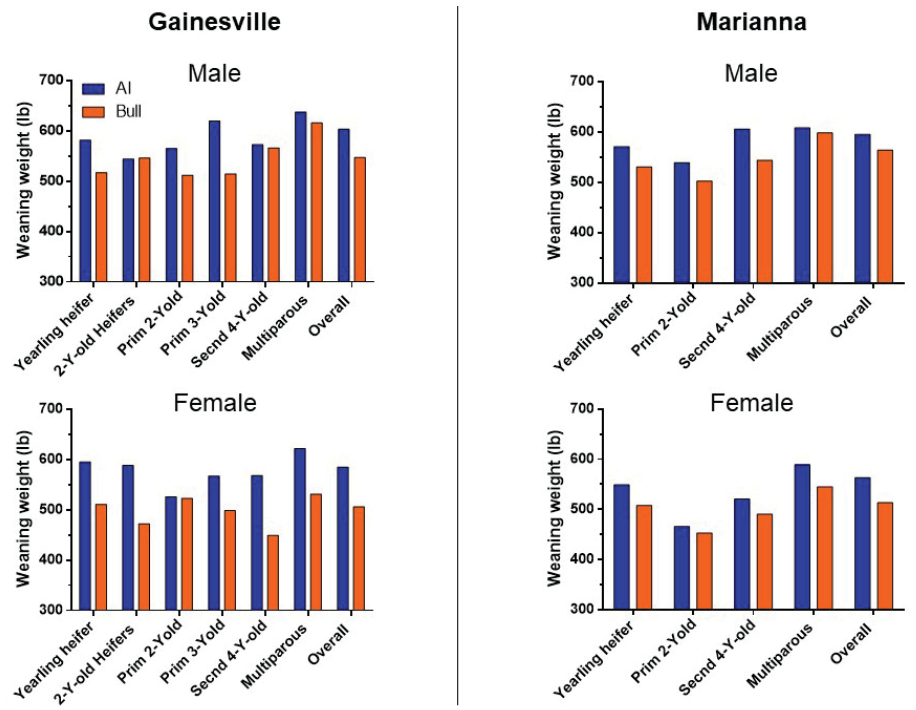

Figure 3. Weaning weights (unadjusted) for male and female calves from both the Gainesville (left panels) and the Marianna (right panels) herds, for each female category. Blue bars correspond to calves born from Al and orange bars correspond to calves sired by natural service. Credits: UF/IFAS

Table 1. Overview of the calf management of the UF Beef Units.

\begin{tabular}{|l|l|l|}
\hline \multicolumn{1}{|c|}{ Variable } & \multicolumn{1}{c|}{ Gainesville } & \multicolumn{1}{c|}{ Marianna } \\
\hline Main breed composition & Angus x Brahman crossbreds & Angus, Brangus, Braford \\
\hline Calving season: Heifers & $\begin{array}{l}\text { Date start: } 11 / 06 / 2019 \\
\text { Date finish: 02/12/2020 }\end{array}$ & $\begin{array}{l}\text { Date start: } 12 / 10 / 2019 \\
\text { Date finish: } 02 / 21 / 2020\end{array}$ \\
\hline Calving season: Cows & $\begin{array}{l}\text { Date start: } 12 / 09 / 2019 \\
\text { Date finish: 03/27/2020 }\end{array}$ & $\begin{array}{l}\text { Date start: } 12 / 08 / 2019 \\
\text { Date finish: } 03 / 22 / 2020\end{array}$ \\
\hline Duration of calving season: Heifers (days) & 98 & 73 \\
\hline Duration of calving season: Cows (days) & 109 & 105 \\
\hline $\begin{array}{l}\text { Average duration of calving season (cow and } \\
\text { heifer) }\end{array}$ & 142 days & 105 days \\
\hline Date of weaning & $08 / 17 / 2020$ & $09 / 04 / 2020$ \\
\hline Age at weaning (days; average) & 234 days & 227 days \\
\hline Age at weaning (days; range) & 143 to 285 days & 166 to 271 days \\
\hline
\end{tabular}

